\title{
The synthesis of phthalocyanines at room temperature
}

\author{
Clifford C. Leznoff,* Mougang Hu and Kieran J. M. Nolan
}

Department of Chemistry, York University, North York (Toronto), Ontario, Canada M3J IP3

Condensation of 4-substituted phthalonitriles with lithium 2-N,N-dimethylaminoethoxide in 2-N, $\mathrm{N}$-dimethylaminoethanol gives a non-statistical mixture of tetrasubstituted phthalocyanines at room temperature or lower while 3-substituted phthalonitriles similarly condense with lithium octan-1-olate in octan-1-ol giving 1,8,15,22-tetrasubstituted phthalocyanines as pure isomers.

Classically, phthalocyanines (Pcs) have been prepared by high temperature $\left(200-300^{\circ} \mathrm{C}\right)$ fusion methods from phthalic anhydride or its derivative ${ }^{1}$ or by condensation of phthalonitriles with lithium pentan- 1 -olate in refluxing pentan-1 -ol $\left(135^{\circ} \mathrm{C}\right) .^{2.3}$ 1,3-Diiminoisoindolines, prepared from phthalonitriles, are readily condensed to phthalocyanines in refluxing $2-N, N$. dimethylaminoethanol (DMAE) $\left(135^{\circ} \mathrm{C}\right) .^{4.5}$ Lower temperature synthesis of phthalocyanines in refluxing butan-1-ol $\left(80^{\circ} \mathrm{C}\right)$ using DBU ${ }^{6.7}$ as a base is also common. Other low temperature synthesis include the use of 1,3,3-trichloroisoindolines, ${ }^{8}$ 1-imino-3-methylthio-6-neopentoxyisoindoline, ${ }^{9}$ or UV methods ${ }^{10}$ but all give phthalocyanines in low yields, use complex apparatus or require poorly accessible starting materials.

Condensation of 4- and 3-substituted phthalonitriles typically give a mixture of four different regioisomers. "It has recently been shown that bulky substituents in 3-substituted phthalonitriles promotes single isomer formation ${ }^{12}$ upon condensation at $75^{\circ} \mathrm{C}$ in octan-1-ol.

The development of a routine phthalocyanine synthesis at room temperature or lower would be important in that temperature sensitive substituents on the precursor phthalonitrile could be used, the extent of impurities formed at higher temperatures could be reduced, impurities which are difficult to remove could thus be eliminated, and the possibilities of forming single isomer phthalocyanines incorporating a wide variety of substituents would be enhanced.

In condensations in our laboratory using diminoisoindolines in DMAE, we had noticed that phthalocyanine formation begins to occur at a temperature as low as $90^{\circ} \mathrm{C}$ even though the standard procedure is accomplished at $135^{\circ} \mathrm{C}$. We thought of preparing the alkoxide of this solvent with lithium metal and using this alkoxide in phthalocyanine formation, a seeming trivial modification of existing protocol but one that has important ramifications. We subsequently showed that lithium octan-1-olate in octan-1-ol was also successful for phthalocyanine formation at room temperature but that lithium pentan1-olate in pentan-1-ol or lower molecular weight alkoxides in lower alcohols did not give phthalocyanines at lower temperatures in accordance with the literature, ${ }^{1,2}$ Thus, condensation of phthalonitrile 1,4 -neopentoxyphthalonitrile ${ }^{13} 2$ or 4 -nitrophthalonitrile 3 in lithium DMAE at 50,20 or $3^{\circ} \mathrm{C}$ and 3-neopentoxyphthalonitrile ${ }^{14} \quad 4, \quad 3$-p-butylbenzyloxyphthalonitrile ${ }^{12} 5$ or 3-methoxyphthalonitrile ${ }^{15} 6$ in lithium octan-1-olate in octan-1-ol at $20^{\circ} \mathrm{C}$ readily took place. Normal work-up of the reactions from 1-3 gave phthalocyanine 7 , 2,9,16,23-tetraneopentoxyphthalocyanine ${ }^{13} \quad 8 \quad$ and 2,9,16,23-tetranitrophthalocyanine ${ }^{5,16} 9$, while treatment of the reactions from 4-6 with zinc acetate gave 1,8,15,22-tetraneopentoxyphthalocyaninato zinc(II) $\quad 10$, $1,8,15,22$-tetra( $p$-butylbenzyloxy) phthalocyaninato $\operatorname{zinc}(\mathrm{II})^{12}$
11 and 1,8,15,22-tetramethoxyphthalocyaninato $\mathrm{zinc}(\mathrm{II})^{15} 12$ respectively, (Scheme 1), in $8-56 \%$ yield (Table 1). The lower the temperature of the reaction, the longer time is required. A typical procedure for the low temperature synthesis is described. $\dagger$

Analysis of the phthalocyanines by 'H NMR spectroscopy revealed that 8 and 9 existed as a non-statistical mixture of isomers but that $10, \ddagger 11$ and $12 \ddagger$ were produced as pure single isomers, 10 and 12 for the first time. The ${ }^{13} \mathrm{C}$ NMR spectrum of the aromatic region of $10+$ is shown in Fig. 1 and compared with that of 10 prepared at high temperature, which gave a mixture of isomers.

It had been previously assumed that the formation of a pure isomer of a 1,8,15,22-tetrasubstituted phthalocyanine was due to the steric bulk of the 3 -substituent, preventing the formation of other sterically constrained regiomers. ${ }^{12}$ It is possible that electronic effects are important in the cyclic condensation of the phthalonitrile. This idea gained some credence when condensation of the sterically less demanding 6 also yielded 12 as a single isomer. Further studies on the mechanism of low temperature phthalocyanine formation are in progress.

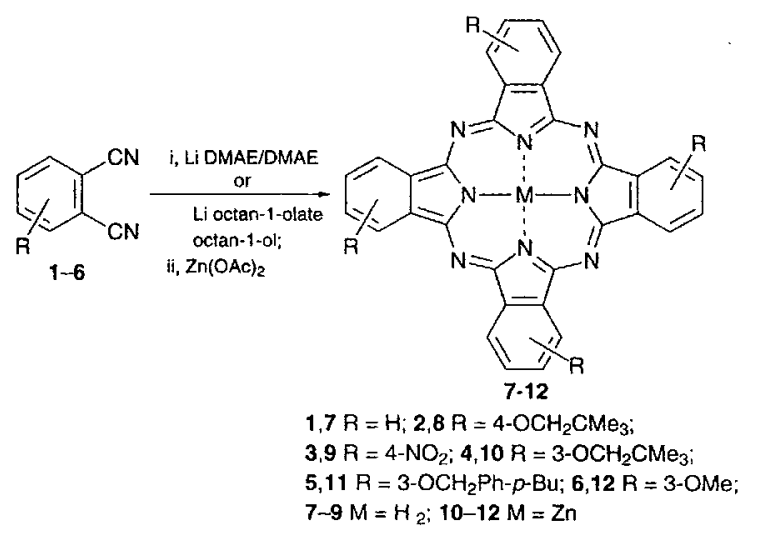

Scheme 1

Table 1 Low temperature preparation of phthalocyanines

\begin{tabular}{rcrll}
\hline $\mathrm{P}^{a}$ & $T /{ }^{\circ} \mathrm{C}$ & $t^{b}$ & Solvent & Yield $(\%)$ \\
\hline $\mathbf{7}$ & 50 & $24 \mathrm{~h}$ & DMAE & 56 \\
$\mathbf{7}$ & 20 & $24 \mathrm{~h}$ & DMAE & 16 \\
7 & $3-5$ & $72 \mathrm{~h}$ & DMAE/THF & 10 \\
$\mathbf{8}$ & 50 & $24 \mathrm{~h}$ & DMAE & 36 \\
$\mathbf{8}$ & 20 & $4 \mathrm{~d}$ & DMAE & 15 \\
$\mathbf{8}$ & $3-5$ & $8 \mathrm{~d}$ & DMAE & 10 \\
$\mathbf{9}$ & 20 & $3 \mathrm{~d}$ & DMAE/Dioxane & 38 \\
$\mathbf{9}$ & $3-5$ & $3 \mathrm{w}$ & DMAE/THF & 45 \\
$\mathbf{1 0}$ & 20 & $7 \mathrm{~d}$ & octan-1-ol & 18 \\
$\mathbf{1 1}$ & 20 & $7 \mathrm{~d}$ & octan-l-ol & 13 \\
$\mathbf{1 2}$ & 20 & $7 \mathrm{~d}$ & octan-l-ol & 8 \\
\hline
\end{tabular}

a Concentrations of the precursor phthalonitriles $1-3$ were $250 \mathrm{mg} \mathrm{ml}^{-1}$, while those of $4-6$ were $40 \mathrm{mg} \mathrm{ml}^{-1}$. ${ }^{\circ}$ Hours (h), days (d), weeks (w). 

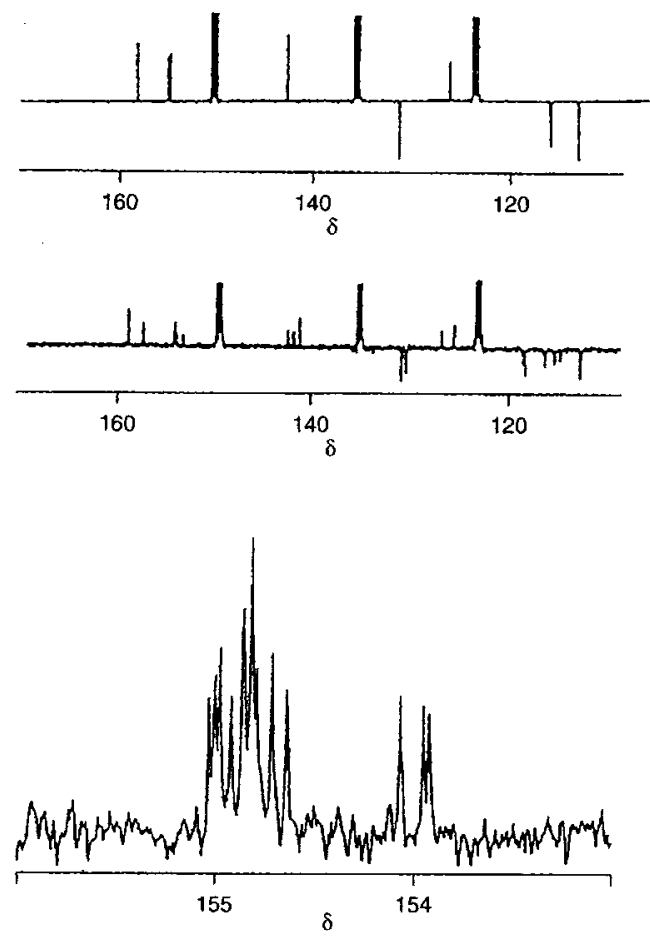

Fig. $1^{13} \mathrm{C}$ NMR spectra of the aromatic region of the pure isomer, 1,8,15,22-tetraneopentoxyphthalocyanine 10 (top) (only two $\mathrm{N}-\mathrm{C}-\mathrm{N}$ carbon absorptions at $\delta 154.97$ and 154.73; of 10 as a mixture of regioisomers (middle); of the intemal $\mathrm{N}-\mathrm{C}-\mathrm{N}$ carbon absorptions of 10 as a mixture of regioisomers (bottom). Pyridine absorptions occur at $\delta 150.35$, 135.91 and 123.87 .

The authors acknowledge the Natural Sciences and Engineering Research Council of Canada for financial support.

\section{Footnotes}

† A suspension of $0.02 \mathrm{~g}$ of lithium in $3.0 \mathrm{ml}$ of octan- 1 -ol was heated to $170^{\circ} \mathrm{C}$ and stirred until a homogeneous solution was obtained. The solution was cooled to $20^{\circ} \mathrm{C}$ and $150 \mathrm{mg}$ of $4 \mathrm{in} \mathrm{I} \mathrm{ml}$ of THF was added. The mixture was stirred for 7-10 d, after which excess zinc acetate was added and the mixture stirred for another $2-3 \mathrm{~d}$. The reaction was quenched with methanol and water $(1: 1)$ and washed with methanol. The crude products were purified by column chromatography on silica gel and 10 was obtained as a blue solid in $18 \%$ yield. Recrystallization of 10 from benzene gave blue needles.
¥ Satisfactory spectroscopic data were obtained for all compounds and elemental analysis for the new single isomers 10 and 12. Selected spectroscopic data for 10: UV-VIS (THF) $\lambda_{\max } / \mathrm{nm}(\log \varepsilon) 698$ (5.24), 662 (4.30), 622 (4.26) and 365 (4.12); IR v/ $\mathrm{cm}^{-1}$ (KBr) 3010, 2920, 2840, 2820, I575, 1480, 1335, 1255, 1230, 1130,1090, 1060, 1040, 1020,800,760 and 735; ' $\mathrm{H}$ NMR (400 MHz, [ $\left[\mathrm{H}_{5}\right]$ pyridine) $\delta 9.72(\mathrm{~d}, 4 \mathrm{H}, J 7.4 \mathrm{~Hz}), 8.34(\mathrm{t}$ $4 \mathrm{H}, J 7.4 \mathrm{~Hz}), 7.76(\mathrm{~d}, 4 \mathrm{H}, J 7.8 \mathrm{~Hz}), 4.37(\mathrm{~s}, 8 \mathrm{H})$ and $1.72(\mathrm{~s}, 36 \mathrm{H}):{ }^{13} \mathrm{C}$ NMR (100.6 MHz [ $\left.{ }^{2} \mathrm{H}_{5}\right]$ pyridine) $8158.10,154.97,154.73,142.85,132.00$, $126.47,116.90,113.25,79.70,33.32$ and 27.35 ; FAB-MS for $\mathrm{C}_{52} \mathrm{H}_{56} \mathrm{~N}_{8} \mathrm{O}_{4} \mathrm{Zn} m / 2$ (relative intensity, \%) $920\left(\mathrm{M}^{+}, 100\right)$. For 12: UV-VIS (THF) $\lambda_{\max } / \mathrm{nm}(\log \varepsilon) 694(5.24), 662$ (4.37), 62 (4.43) and 368 (4.37); IR $v / \mathrm{cm}^{-1}(\mathrm{KBr}) 3010,2920,2840,2820,1575,1480,1335,1262,1230,1130$ $1090,1060,1040,1020,800.760$ and $735 ; 1 \mathrm{H}$ NMR $(400 \mathrm{MHz}$, $\left[{ }^{2} \mathrm{H}_{5}\right.$ ]pyridine) $\delta 9.55(\mathrm{~d}, 4 \mathrm{H}, J 8.0 \mathrm{~Hz}), 8.18(\mathrm{t}, 4 \mathrm{H}, J 8.0 \mathrm{~Hz}), 7.69(\mathrm{~d}, 4$ $\mathrm{H}, J 7.9 \mathrm{~Hz})$ and $4.58(\mathrm{~s}, 8 \mathrm{H}) ;{ }^{13} \mathrm{C}$ NMR $\left(100.6 \mathrm{MHz}\left[{ }^{2} \mathrm{H}_{5}\right]\right.$ pyridine $\delta$ $156.85,155.07,154.89,142.93,132.03,127.04,117.24,113.81$ and 56.88; $\mathrm{FAB}-\mathrm{MS}$ for $\mathrm{C}_{36} \mathrm{H}_{24} \mathrm{~N}_{8} \mathrm{O}_{4} \mathrm{Zn} m / \bar{z}$ (relative intensity, \%) $696\left(\mathrm{M}^{+}, 100\right)$.

\section{References}

1 C. C. Leznoff, in Phthalocyanines: Properties and Applications, ed. C. C. Leznoff and A. B. P. Lever, VCH. New York, 1989, p. L:F.H. Moser and A. L. Thomas, The Phthalocyanines, vol, 1, 2, CRC, Boca Raton, 1983

2 R. P. Linstead and A. R. Lowe, J. Chem. Soc., 1934, 1022.

3 N. B. McKeown, I. Chambrier and M. J. Cook, J. Chem. Soc., Perkin Trans. $1,1990,1169$.

4 J. A. Elvidge and R. P. Linstead, J. Chem. Soc., 1955, 3536

5 P. J. Brach, S. J. Grammatica, O. A. Ossanna and L. Weinberger, J. Heterocyclic Chem., 1970, 7. 1403.

6 H. Tomoda, S. Saito, S. Ogawa and S. Shiraishi, Chem. Lett., 1980. 1277.

7 T. G. Linssen, K. Dürr, M. Hanack and A. Hirsch. J. Chem. Soc.. Chem. Commun., 1995, 103.

8 E. M. IdeIson, US PAT, 1977, 4061 654; Chem. Abstr., 1977, 88, $171797 \mathrm{~m} ;$ J. G. Young and W. Onyebuagu, J. Org. Chem., 1990, 55 2155.

9 S. Greenberg, A. B. P. Lever and C. C. Leznoff, Can. J. Chem., 1988, 66, 1059.

10 H. Tomoda, S. Saito and E. Hibiya, Chem. Lett., 1976, 1003.

11 D. Wöhrle, J. Gitzel, I. Okuro and S. Aono, J. Chem. Soc., Perkin Trans 2, 1985, 1171; M. Hanack, D. Meng, A. Beck, M. Sommeraur and L. R. Subramanian, J. Chem. Soc., Chem. Commun., 1993, 58; M. Hanack, G. Schmid and M. Sommerauer, Angew'. Chem., Int. Ed. Engl., 1993, 32. 1422 .

12 C. C. Leznoff, M. Hu, C. R. McArthur, Y. Qin and J. E. van Lier, Can. J. Chem., 1994, 72, 1990.

13 C. C. Leznoff, S. M. Marcuccio, S. Greenberg, A. B. P. Lever and K. B. Tomer, Can. J. Chem., 1985, 63, 623.

14 C. C. Leznoff and D. M. Drew, Can. J. Chem., 1996, 76, 307.

15 V. M. Derkacheva, O. L. Kaliya and E. A. Luk'yanets, Zh. Obshch. Khim., 1983, 53, 188.

16 S. W. Oliver and T. D. Smith, J. Chem. Soc., Perkin Trans. 2, 1987, 1579 


\title{
Synthesis and NMR Studies of a Single Isomer of an Alkynyl Substituted Binuclear Phthalocyanine
}

\author{
HIROAKI ISAGOT, DMITRI S. TEREKHOV and CLIFFORD C. LEZNOFF* \\ Department of Chemistry, York University, North York (Toronto), ON M3J 1P3, Canada
}

\begin{abstract}
By a mixed condensation of 1,3-bis( $3^{\prime}, 4^{\prime}$-dicyanophenoxy)-2-ethyl-2-methylpropane with a

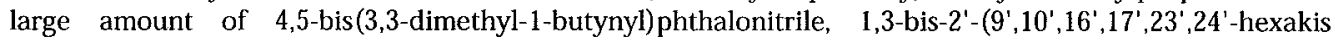
(3",3"-dimethyl-1"-butynyl) phthalocyaninoxyl)-2-ethyl-2-methylpropane, was synthesized as a binuclear phthalocyanine having a single isomer. NMR studies at various temperatures and concentrations suggested that the interactions between the phthalocyanine macrocycles were dominated by intermolecular aggregation at lower temperatures or high concentrations whereas intramolecular aggregation was predominant at higher temperatures or lower concentrations. (C) 1997 by John Wiley \& Sons, Ltd.
\end{abstract}

J. Porphyrins Phthalocyanines, Vol. 1, 135-140 (1997) (No. of figures: 5 No. of tables: 0 No. of refs: 7)

KEYWORDS: binuclear; phthalocyanine; intramolecular interactions

\section{INTRODUCIION}

Aggregation is a well-known phenomenon in phthalocyanine $(\mathrm{Pc})$ chemistry [1]. Interactions can occur between adjacent phthalocyanine macrocycles in media, resulting in coupling between the electronic states of more than one phthalocyanine nucleus. Binuclear phthalocyanines have attracted much attention as a probe for examining the degree of intramolecular interaction and the extent of electronic coupling between the two macrocycles of the binuclear molecule. Binuclear phthalocyanines may be important in designing multi-electron redox catalysts for electrocatalytic [2] and photocatalytic processes and studying energy transfer in biological systems.

Although a number of binuclear phthalocyanines, linked by bridges of different length, have been reported so far [3], they were mixtures of regioisomers, the presence of which have made the interpretations of the observed physical or physicochemical properties more difficult [4]. Known binuclear phthalocyanines that were prepared have

This paper is dedicated to Prof. Dr. Michael Hanack on the occasion of his 65 th birthday

$\dagger$ A visiting scholar from the National Research Institute for Metals, 1-2-1, Sengen, Tsukuba, Ibaraki 305 Japan.

${ }^{*}$ Correspondence to: C. C. Leznoff. only one substituent on each peripheral benzene ring to improve their solubility in organic solvents, useful for physical or physicochemical measurements.

In this paper, we wish to report the synthesis of a binuclear phthalocyanine which is highly soluble in common organic solvents and forms only one isomer. Isolation of a single isomer binuclear $\mathrm{Pc}$ enabled us to study in more detail the NMR spectroscopy of the binuclear phthalocyanine for the first time. Monitoring of inter- and intramolecular interactions between phthalocyanine macromolecules by NMR spectroscopy is reported.

\section{RESULTS AND DISCUSSION}

Mixed condensation of 1,3-bis ( $3^{\prime}, 4^{\prime}$-dicyanophenoxy)-2-ethyl-2-methylpropane, (1), with a 20-fold excess of 4,5-bis (3',3'-dimethyl-1'-butynyl) phthalonitrile, (2) [5] with lithium 1-pentoxide in 1-pentanol at $100^{\circ} \mathrm{C}$ gave the binuclear metal-free phthalocyanine, 1,3-bis-2'-(9',10',16',17',23',24-hexakis(3", 3"dimethyl-1" -butynyl)phthalocyaninoxy)-2-ethyl-

2-methylpropane (3) in 3.5\% yield (Scheme 1). Mononuclear metal-free 2,3,9,10,16,17,23,24-octakis (3',3'-dimethyl-1'-butynyl) phthalocyanine (hereafter referred to as mononuclear phthalocyanine), which formed as a by-product, had to be 
removed to purify the desired binuclear phthalocyanine.

As 4 is less soluble in tetrahydrofuran (THF) than 3 , the desired binuclear phthalocyanine was effectively concentrated into THF solution from the reaction mixture. Attempts to separate the phthalocyanines from each other by gel permeation chromatography (GPC) were unsuccessful because of poor resolution, maybe due to aggregation phenomena. The best separation was achieved by flash chromatography when it was performed on a small scale (less than $200 \mathrm{mg}$ ). The chromatographic separation on a large scale (>500 mg) was unsuccessful because of the relatively low solubility of $\mathbf{4}$ in the solvent system (toluene/hexane 1:1) used as an eluent. As expected, the binuclear phthalocyanine obtained in this way was pure and composed of only one isomer, as was shown by its NMR spectrum. The NMR spectrum of $\mathbf{3}$ is characteristic of a heptasubstituted Pc.

The electronic absorption spectrum of the binuclear phthalocyanine 3 in benzene is shown in Fig. 1 . A quite broad absorption band was observed in the $600-700 \mathrm{~nm}$ region with an absorption maximum at $698 \mathrm{~nm}$. Dilution of the solution did not exhibit any changes in its spectral patterns. Although the known mononuclear metal-free phthalocyanines show a pair of sharp Q-bands in the same region $[4,6]$, this is not the case for 3 . However, it is understandable if a closed clam-shell conformation is assumed within a molecule because of a strong exciton coupling between the two chromophores of the Pc nucleii [4]. An alternative possibility that the binuclear phthalocyanine molecules aggregate to each other even in<smiles>CCC(C)(COc1ccc(C#N)c(C#N)c1)COc1ccc(C#N)c(C#N)c1</smiles><smiles>[R]C#Cc1cc(C#N)c(C#N)cc1C#C[R]</smiles>

$2 \mathrm{R}=$ tert-butyl

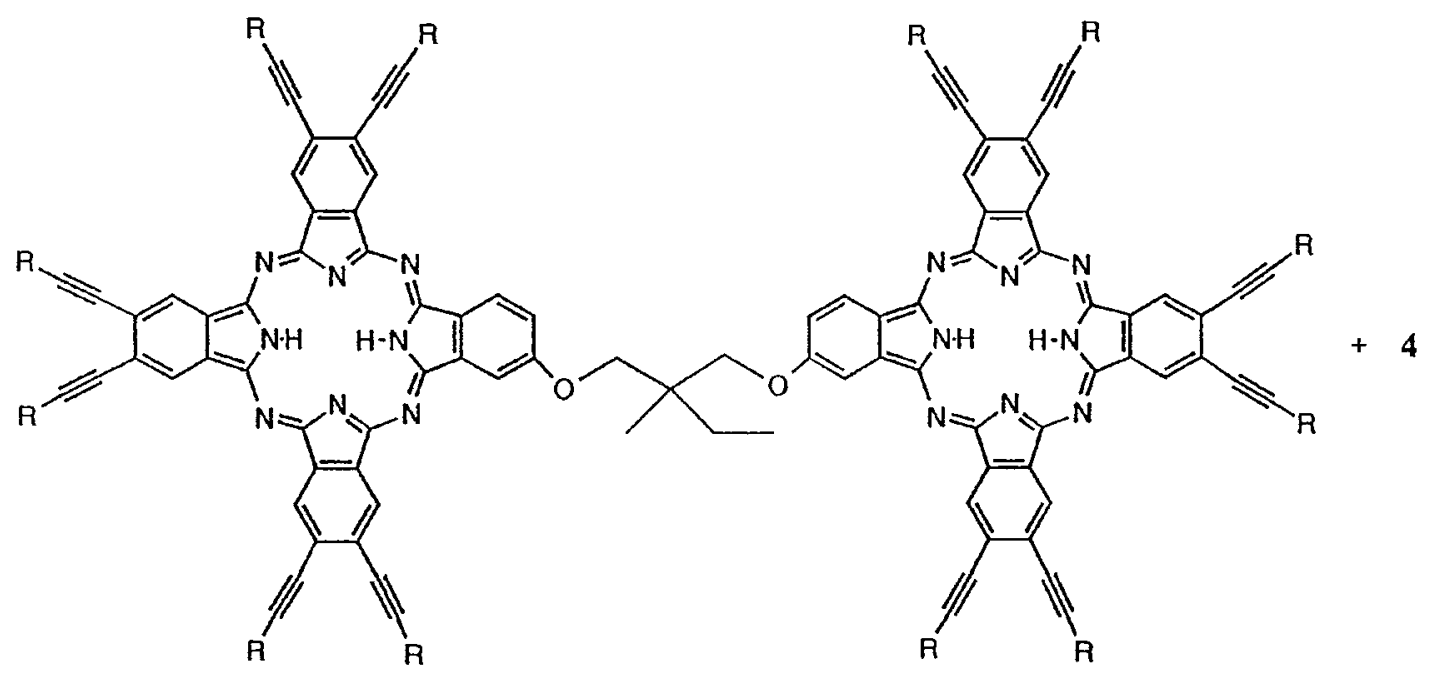

$3 \mathrm{R}=$ tert -butyl

Scheme 1. 


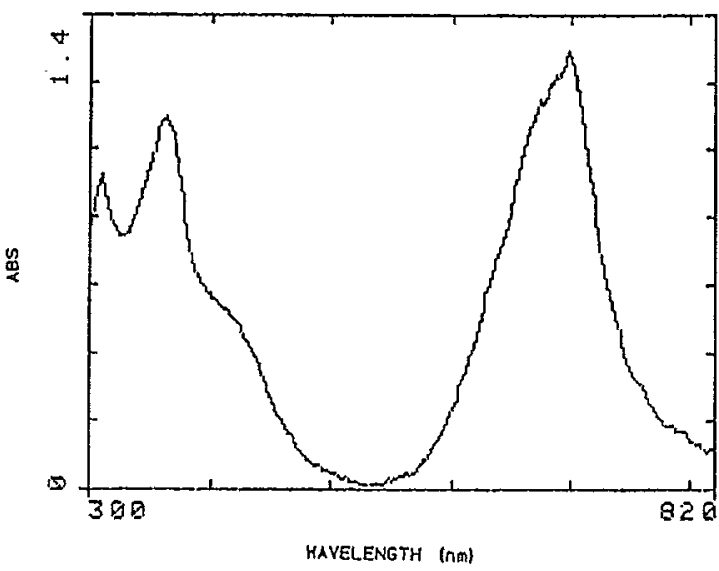

Fig. 1. An electronic absorption spectrum of the binuclear phthalocyanine 3 in benzene solution.

this concentration range $\left(10^{-5} \mathrm{~mol} \mathrm{l}^{-1}\right)$ is successfully eliminated by the NMR studies described below.

Typical NMR spectra of binuclear metal-free phthalocyanine $\mathbf{3}$ in benzene- $d_{6}$ are shown in Fig. 2. Although the spectra observed varied regularly depending on the temperature and concentration of the solutions used for the measurements (better resolution was obtained either at a higher temperature or with a lower concentration of the solution used), their spectral aspects were essentially the same: six singlets, two doublets and one multiplet were observed in the aromatic region (some signals overlapped with each other under some conditions) (Fig. 2a); and six singlets (attributable to tert-butyl protons), one singlet (methyl protons of the methyl group in the bridge) and one triplet (methyl protons of the ethyl group in the bridge) in an aliphatic region (some signals overlapped with each other in some conditions) (Fig. 2b); and one AA'BB' pattern multiplet attributable to $-\mathrm{OCH}_{2}$ - prochiral protons in the 4.0-4.5 ppm region (Fig. 2c); and one singlet attributable to the inner protons in the -2.0 to -3.5 ppm range (Fig. 2d). These data are consistent with the desired structure of the binuclear metal-free phthalocyanine because the six protons on the benzene rings and the six tert-butyl groups in the three, 4,5-dialkynylbenzo moieties are all different in the binuclear phthalocyanine 3 because of the presence of the seventh bridging group. Although no signal of the methylene protons of the ethyl group of the bridging group was observed, its COESY spectrum clearly showed the presence of strong coupling between the triplet signals and some signals hidden by one of the intense tert-butyl protons. The COESY spectrum also showed the presence of coupling between the doublet at around $7.5 \mathrm{ppm}$ and the multiplet at around $8.0 \mathrm{ppm}$ in the aromatic region.

As stated above, the NMR spectra showed both temperature and concentration dependence. Figure $3 \mathrm{a}$ and $\mathrm{b}$ show the concentration dependence of the chemical shifts of the inner imino protons and some of the aromatic protons of the binuclear phthalocyanine in benzene- $d_{6}$ solutions. Although the signal shifted downfield in the high concentration region $\left(10^{-2}-10^{-4} \mathrm{~mol} \mathrm{l}^{-1}\right)$ as the concentration was lowered, it remained unchanged in the low concentration region $\left(10^{-4}-10^{-6} \mathrm{~mol}^{-1}\right)$. In the previous paper [5], it was reported that the chemical shifts of both the inner and aromatic protons of mononuclear octaalkynyl-substituted phthalocyanines shifted downfield as their concentration was lowered. These shifts have been successfully explained in terms of aggregation phenomena of phthalocyanine macrocycles $[1,5]$. However, no such saturation phenomena against varied concentration was observed for any mononuclear phthalocyanines. Therefore, the saturation phenomenon is attributed to some preferred cofacial conformation of the binuclear phthalocyanine in solution.

A similar saturation phenomenon was observed when a nitrobenzene- $d_{5}$ solution containing the binuclear phthalocyanine was heated up to $420 \mathrm{~K}$ (Fig. 4). Although the inner protons did not show a clear saturation up to $420 \mathrm{~K}$, the chemical shift seems close to saturation around $-2 \mathrm{ppm}$, the value of which is much lower than those of the known mononuclear phthalocyanines [5].

Thus, both the concentration- and temperaturedependence studies showed that the chemical shifts of the protons in binuclear phthalocyanine 3 reach constant chemical shift values much earlier than the known related mononuclear phthalocyanines. These phenomena are rationalized by assuming two types of interaction between the phthalocyanine macrocycles; one is an intermolecular interaction between a phthalocyanine macrocycle in a molecule and that in other molecules, and another is an intramolecular interaction between the two macrocycles within a molecule. In a highly concentrated solution, binuclear phthalocyanine molecules are close to each other and hence columns of aggregated phthalocyanine macrocycles would be present in such a solution [5]. Dilution of such a solution will lengthen the distance between phthalocyanines and hence reduce the length of columns. Raising the temperature 
would yield the same effects on the aggregated phthalocyanines because thermal motion of the phthalocyanines would break such columns and hence shorten their length. The effects of both dilution and raising the temperature on the NMR spectra of monomeric phthalocyanines are discussed in detail elsewhere. [5]. The shifts observed in the NMR spectra of the binuclear phthalocyanine 3 in this study either in highly concentrated solutions or at lower temperatures is explained in the same way. On the other hand, neither the inner imino protons nor the aromatic protons showed any shift in dilute solutions. This suggests that each binuclear phthalocyanine molecule is free from any interaction with the other molecules. Nevertheless, the chemical shifts of the inner protons of 3 plateau more upfield by $1 \mathrm{ppm}$ than that of the mononuclear phthalocyanine 4 under the same conditions [5], indicating that a phthalocyanine macrocycle is still under some type of interaction, which is attributable to intramolecular aggregation of the two phthalocyanine macrocycles in the molecule.

\section{EXPERIMENTAL}

The FAB-mass spectrum of the binuclear phthalocyanine $\mathbf{3}$ was measured by Dr B. Khouw (York University, North York, Ontario, Canada). NMR and
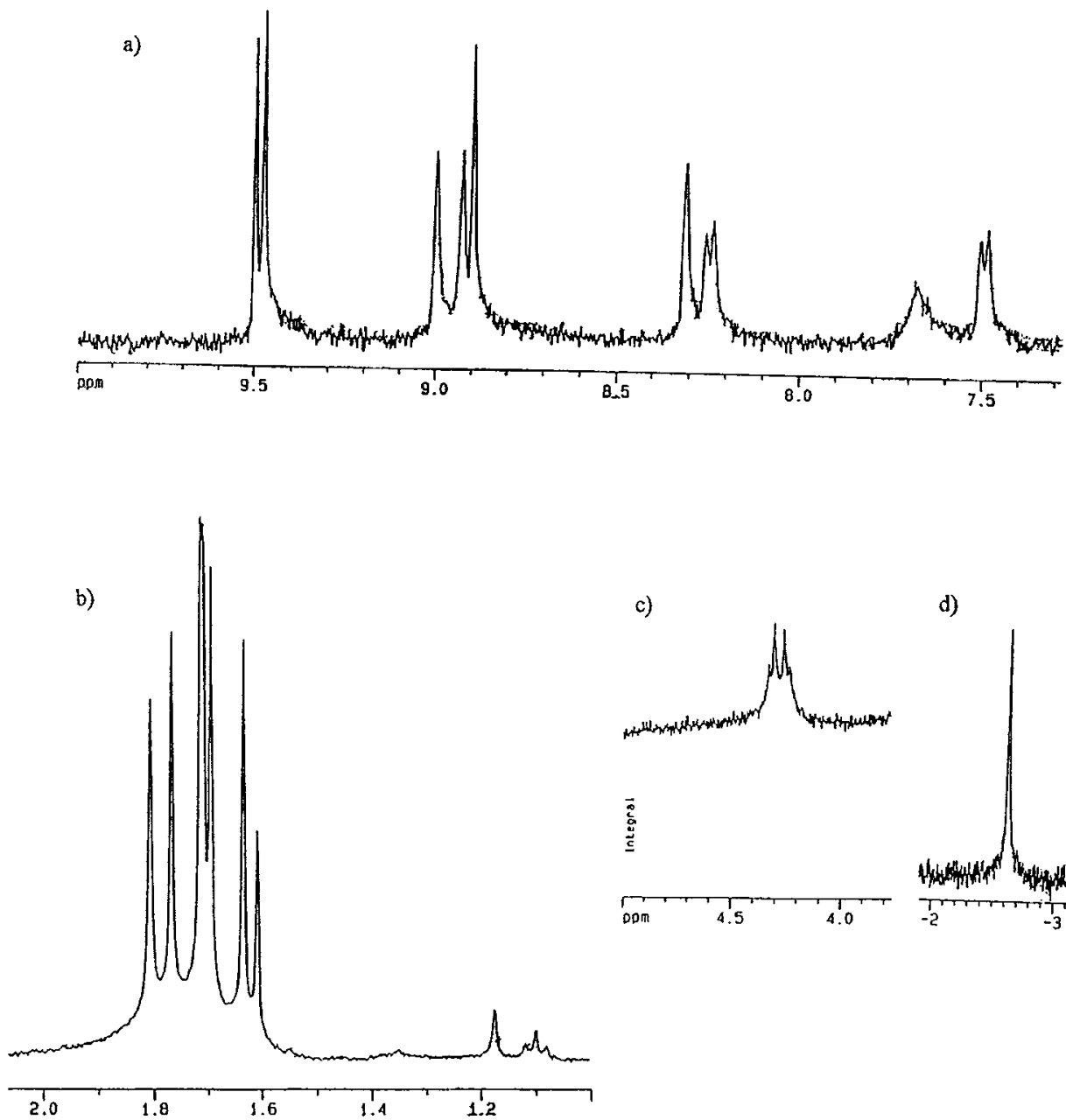

c)

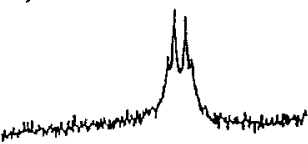

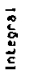
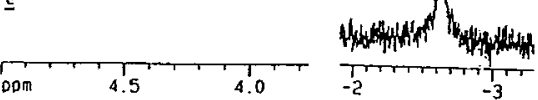

Fig. 2. Typical NMR spectra of the binuclear phthalocyanine in benzene- $d_{6}$ : (a) aromatic region, $330 \mathrm{~K}$ [phthalocyanine] $=9.44 \times 10^{-4} \mathrm{~mol} \mathrm{I}^{-1}$; (b) aliphatic region, $330 \mathrm{~K}, 2.36 \times 10^{-4} \mathrm{~mol} \mathrm{I}^{-1}$; (c) prochiral protons, 340 $\mathrm{K}, 6.15 \times 10^{-3}$ and $\mathrm{moll}^{-1}$; (d) inner imino protons, $330 \mathrm{~K}, 9.44 \times 10^{-4} \mathrm{~mol} \mathrm{I}^{-1}$. 

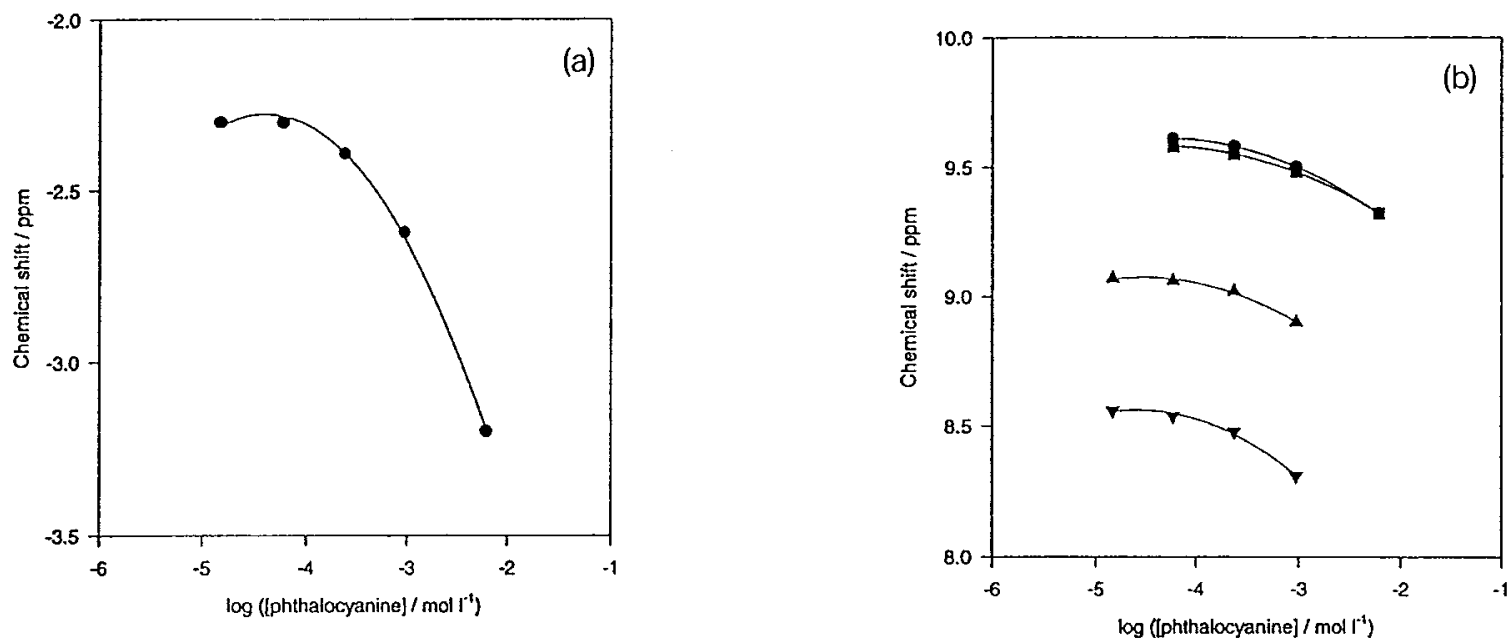

Fig. 3. Plots of chemical shifts of (a) inner imino protons of the binuclear phthalocyanine 3 and (b) some aromatic protons of the binuclear phthalocyanine 3 in benzene- $d_{6}$ against concentration on a logarithmic scale.

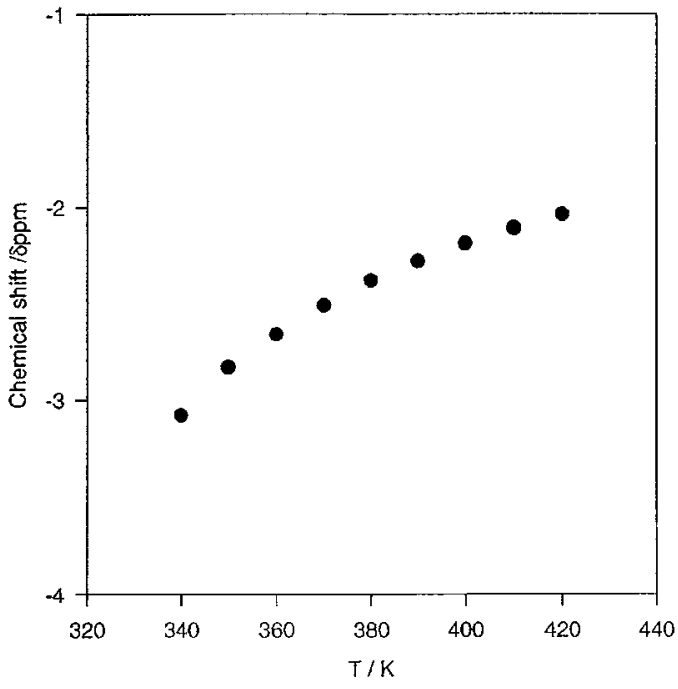

Fig. 4. Plot of chemical shifts of the inner imino protons of the binuclear phthalocyanine 3 in nitrobenzene- $d_{5}$ against temperature.

COESY spectra were measured using a Bruker ARX 400 high field Fourier transform instrument.

\section{1,3-Bis-2'-(9',10',16',17',23',24'-hexakis(3", 3"-dimethyl-1-butynyl)phthalocyaninoxy)- 2-ethyl-2-methylpropane (3)}

The starting phthalonitriles 1 [7] and 2 [5] were prepared according to the literature $[5,7]$. To a suspension of $0.1 \mathrm{~mol}$ of lithium 1-pentoxide in $10 \mathrm{ml}$ of 1-pentanol was added a mixture of $1.6 \mathrm{~g}(5.6$ $\mathrm{mmol})$ of 2 and $100 \mathrm{mg}(0.30 \mathrm{mmol})$ of 1 which had been previously well-ground altogether. The mixture was stirred at $100^{\circ} \mathrm{C}$ for $4 \mathrm{~h}$ under an argon atmosphere. After the mixture was cooled down to room temperature, the reaction was quenched by the addition of methanol, concentrated hydrochloric acid and ethanol (1:1:1). The blue precipitate obtained in this way was collected by filtration under suction and was successively washed with acetonitrile until the washings turned almost colourless. The remaining solids $(1.5 \mathrm{~g})$ were dissolved in toluene and then chromatographed over silica gel (toluene) to remove impurities which adhered to the silica gel. This procedure was repeated twice. After the solvent was evaporated, the desired binuclear phthalocyanine 3 was extracted from the solids with four $10 \mathrm{ml}$ portions of THF. The residue $(1.3 \mathrm{~g})$ was almost pure mononuclear phthalocyanine 4. Removal of the solvent of the extract under reduced pressure gave $100 \mathrm{mg}$ of solids. This solid was dissolved in THF and chromatographed over SX-4 GPC gel using THF as an eluent. Polynuclear phthalocyanines, the desired binuclear Pc 3, and then mononuclear phthalocyanine 4 were eluted in this order. The fractions containing the second band were collected and the solvent was evaporated under reduced pressure. The remaining solids $(50 \mathrm{mg}$ ) were further purified by flash chromatography to remove a small persistent residue of 4 . A small amount of 4 was eluted with hexane/toluene $(1: 1)$ and then 3 was eluted with hexane/toluene $(1: 3)$. The fractions containing the 
second band were collected and the solvent was evaporated under reduced pressure. The solids obtained in this way were first recrystallized from chloroform/acetonitrile and then from THF/ethanol, washed with ethanol and dried in vacuum at $80^{\circ} \mathrm{C}$. A $20 \mathrm{mg}$ sample of a blue powder 3 was obtained in $3.5 \%$ yield. FAB-MS $m / z 2104\left(\mathrm{M}^{+}\right)$(the exact molecular weight is 2104.8); UV/vis (benzene) $\lambda_{\max }$ in $\mathrm{nm}\left(\log \left(\varepsilon / \mathrm{mol}^{-1} \mathrm{l}^{-1} \mathrm{~cm}^{-1}\right)\right): 310$ (4.84), 364 (4.91), 400 (sh) (c. 4.6), 698 (4.98). Anal. calc. for $\mathrm{C}_{142} \mathrm{H}_{142} \mathrm{~N}_{16} \mathrm{O}_{2}: \mathrm{C}, 81.03, \mathrm{H}, 6.80, \mathrm{~N}, 10.65$; found: $\mathrm{C}$, $81.15, \mathrm{H}, 6.78, \mathrm{~N}, 10.53$.

\section{Acknowledgements}

The authors wish to thank the Natural Science and Engineering Research Council for support of this research.

\section{REFERENCES AND NOTES}

1. M. Abkowitz and A. R. Monahan, J. Chem. Phys. 58, 2281 (1973); E. W. Abel, J. M. Pratt and E. J. Whelan, J. Chem. Soc., Dalton Trans. 509 (1976); R. D. Farina, D. J. Halko and J. H. Swinehart, J. Phys. Chem. 76, 2343 (1972).

2. A. B. P. Lever, E. R. Milaeva and G. Speier, in Phthalocyanines: Properties and Applications (eds C. C. Leznoff and A. B. P. Lever), Vol. 3, VCH, New York, p. 1 (1989).

3. C. C. Leznoff, in Phthalocyanines: Properties and Applications (eds. C. C. Leznoff and A. B. P. Lever), Vol. 1, VCH, New York, p. 393 (1989).

4. E. S. Dodsworth, A. B. P. Lever, P. Seymour and C. C. Leznoff, J. Phys. Chem. 89, 5698 (1985).

5. D. S. Terekhov, K. J. M. Nolan, C. R. McArthur and C. C. Leznoff, J. Org. Chem. 61, 3034 (1996).

6. M. J. Stillman and T. Nyokong, in Phthalocyanines: Properties and Applications (eds C. C. Leznoff and A. B. P. Lever), Vol. 1, VCH, New York, p. 133 (1989)

7. C. C. Leznoff, S. M. Marcuccio, S. Greenberg, A. B. P. Lever and K. B. Tomer, Can. J. Chem. 63, 623 (1985). 